\title{
Measuring the Impact of the Once Only Principle for Businesses Across Borders
}

Tjerk Timan $^{(\otimes)}$, Anne Fleur van Veenstra, and Kristina Karanikolova

Strategy and Policy, Netherlands Institute for Applied Scientific Research TNO, Anna van Buerenplein 1, 2595 DA The Hague, The Netherlands

\{tjerk.timan, annefleur.vanveenstra, kristina.karanikolova\}@tno.nl

\begin{abstract}
The Once-Only Principle (OOP) holds that public administrations ideally collect data from citizens and businesses only once to share this information, within regulatory limits, with other administrative bodies and across Member States. The aim of the OOP is to simplify interaction with public services and contribute to administrative burden reduction. To demonstrate the cross-border application of the OOP for businesses, the Large Scale Pilot European project 'The Once Only Principle Project (TOOP)' develops pilots and identifies benefits and challenges as well as (potential) impacts of the adoption of this principle. In this chapter, we explore an Impact Assessment framework for measuring the impact of the OOP on cross-border services for businesses and subsequently validate this framework with members from the TOOP project. During stakeholder sessions organized for this purpose, we find that the OOP potentially has a high impact on government, e.g. by enabling fraud reduction, yet little is known about the impact of the OOP on businesses, and in particular on its cross-border impact. The expected benefits of the OOP likely emerge on the longer term, making identification of short-term impacts challenging. Nonetheless, based on our findings, we recommend to develop and implement methods and tools to measure the impact on the long-term to increase sustainability of the OOP.
\end{abstract}

Keywords: Once only principle - Impact assessment - Data sharing - Impact frameworks · Impact assessment

\section{Introduction}

The Once Only Principle Project (TOOP) is a Large Scale Pilot (LSP) European project that was carried out between 2017 and 2021 with the objective "to explore and demonstrate the once-only principle through multiple sustainable pilots" [21] to provide a basis for future implementation and wider use of the Once Only Principle (OOP). The pilots developed within the TOOP project focus on cross-border electronic services (e-services) for businesses. They explore use cases that demonstrate the impact of the OOP on doing business across borders, including expected benefits such as decreasing the administrative burden of businesses or making governmental processes more efficient. Impact Assessments aid organizations and governments to better understand the consequences 
of adopting technologies into daily processes and workflows [4]. An important outcome of the project is, thus, to develop and validate an Impact Assessment (IA) framework that contributes to implementation and wider use of the OOP; it provides a basis for IA indicators and formulates recommendations for assessing OOP impacts. Since the TOOP project focuses on the cross-border aspect of the OOP for business, the IA framework also focuses on the cross-border aspect of the OOP for businesses. The development of the IA framework for the OOP across borders was carried out using an action research approach [52]. This means that the development of the IA framework was conducted in parallel to the technical work of the TOOP project and that an approach of diagnosis and intervention was taken, feeding back the policy objectives into the technical goals and vice versa. The OOP is a high-level policy objective and is mentioned as one of the principles stemming from the eGovernment Action Plan [9]. Such overarching principles need technical building blocks to put high-level principles in practice, but also, in turn, influence the effectiveness of policies: "Pilot socio-technical systems are used to prove the viability and the feasibility of some policy objective that requires the usage of Information and Communication Technologies (ICT) platforms in order to be attained" [34]. As part of our action research approach, we set up a series of focus group sessions throughout the project in which we invited project partners to jointly discuss impacts assessment and indicators. The added value of such sessions was to regularly capture key developments within the different pilot projects and to connect these developments with developments in the policy field in order to fine-tune and adjust views on the main impacts of the OOP and their measurability.

The IA framework and its discussion, thus, serves multiple purposes. The first is to guide the adoption of the OOP in cross-border services for businesses based on lessons learnt in the project and its pilots. Secondly, the IA framework contributes to the development of recommendations for the long-term sustainability of project results and its connection to other e-Government initiatives and regulations such as the Single Digital Gateway Regulation (SDGR) [12]. ${ }^{1}$ To this end, this chapter is structured as follows. In the next section, we explore benefits and challenges of the OOP, followed by a section on the how we went about developing an IA framework based on related impact indicators. After presenting the suggested framework, in section four we show how this framework was validated in a series of stakeholder focus groups aimed at discussing the framework and its indicators and connecting them to the TOOP pilots. Section five presents the discussion of the findings. Finally, in the conclusion section, we reflect on the IA methodology and describe impact areas to focus on when implementing the OOP.

\section{The Once-Only Principle: Benefits and Challenges}

The OOP holds that public administrations should aim to collect information from citizens and businesses only once and after that, when needed, share this data with other

1 The SDGR envisions that by the end of 2023, more administrative procedures will be available online, national online procedures will be accessible cross-border and the OOP is applicable to a variety of procedures [12]. In this framework, the TOOP project can be seen as providing inputs and working towards the objectives of the SDGR. 
administrative bodies or reuse it, while respecting privacy regulations and other requirements [20]. Within the EU, cross-border implementation of the OOP implies that all other EU Member States should be able to access and reuse certain data once this data has been collected in one Member State. This data can vary in terms of types of entries or mandatory basic information recorded by Member States due to different historical developments of bureaucratic processes. At minimum, this principle should allow governments to re-use basic registries across Europe. On a Member State level, there have been several initiatives that explore and demonstrate the uptake of the OOP. However, cross-border implementation of this principle has until now been limited [21, 22].

The implementation of the OOP is associated with significant benefits [23]. For businesses, the OOP may result in cost and time savings, thereby reduce their administrative burden [23]. For public organizations, the benefits are efficiency gains as a result of less paper mailing, faster processing, time savings due to decreased need for data collection, improved re-use of data, reduced number of unnecessary data submission demands, process optimization and the removal of duplication of tasks [55]. Such efficiency gains can lead to an increased quality of services, reduction of fraud and/or errors and less discrimination [23]. The TOOP website shows some recent success stories in which Member States in the European Union are using building blocks developed by the project [36], or where countries connected to Europe through the European Economic Area [13], for example, are taking up similar principles to make it easier to process EU applications and vice versa [37].

However, the implementation of the OOP across borders is also associated with several challenges. Especially, technical and interoperability issues are recognized among the most challenging problems for cross-organizational information systems due to their reliance on heterogeneous information and process models [25]. The challenges for the uptake of the OOP in a cross-border context not only stem from the type and the quality of data and underlying processes of data collection and retention, but also from noncompatible ICT infrastructures or differences between concepts and meanings of data (semantic interoperability) and interoperability on both national and international level $[6,34]$. Interoperability is a key element for the success of implementing the OOP within a Member State as well as implementing it across borders. It can be defined as the "ability of different organizations to interact towards mutually beneficial and common goals, which involves the sharing of information and knowledge by means of the exchange of data between their respective ICT systems" [6,34]. Besides applicable to technical aspects, interoperability can also apply to semantics, legal issues and organizational aspects [11].

Concerning technical interoperability, heterogeneity of ICT systems and the lack of national interoperability and national systems not meeting the OOP requirements are obstacles that affect EU-wide implementation of the OOP [6, 34]. Regarding semantic interoperability, the main challenge is to enable semantic interoperability between the IT systems of different governments on both a data-structure and data-label level (how are categories filled, what data formats are used etc.) as on a linguistic level [20]. Legal interoperability refers to organizations operating under different legal frameworks, policies and strategies, meaning public services may fall under different governmental departments and/or legal frames in the Member States. Organizational interoperability refers 
to the way in which public administrations align their business processes, responsibilities and expectations to achieve common goals [19]. In general, public sector organizations vary significantly in their requirements due to factors such as organizational and legal structure, size, legacy systems, topic/sector addressed, to name a few. This means that the solutions to enable cross-border OOP have to be highly compatible with, and adaptable to national and local existing ICT solutions and infrastructures [21]. Next to interoperability, there are other challenges, ranging from user acceptance and expectations to public administration progress in adopting certain processes and common semantics, and the uptake and implementation of digital innovation for government. In order to anticipate on potential impacts of novel technologies or principles such as the OOP, a go-to approach is to conduct an Impact Assessment (IA). To do this, an IA framework was developed by identifying impact indicators for TOOP.

\section{Assessing Impact: Developing a Framework for the OOP}

\subsection{The Use of Impact Assessments (IA) for Technology and Policy}

Impact Assessments (IA's) are often used in the process of policy making to evaluate policy options, such as deployed by the OECD [27] and the European Commission (EC) [10], as well as to assess the impact of (new) technologies [4, 40]. Typically, the EC performs IA's on initiatives that are "expected to have significant economic, social or environmental impact" [10]. The OECD uses them to "describe the cascade of cause and effect leading from an intervention to its desired effects" [27]. While an IA mainly focuses on whether an initiative achieves its expected benefits, other aspects also need to be taken into account, since impacts can be positive or negative, and intended or accidental [33]. This means that the scope of an IA can go beyond benefits only, while often being used to investigate the impact of a specific intervention to realize change $[27,33]$. For TOOP, this would mean that an IA helps in a better understanding and anticipation of potential changes in day-to-day government processes once the OOP is implemented. The development of an IA for the OOP as an information system means that it is a technical impact assessment [3] as well as a policy impact assessment, which means that policy goals are inherently tied to, and shaped by, the information systems they are channeled through.

Often IA's are performed in relation to specific issues, e.g. to investigate the impact of a policy on the environment, or to determine socio-economic effects of introducing a new technology $[2,16]$. Since we are assessing a policy action as well as a technological implementation that is framed as a principle, potentially connecting to many other public services, the framing of the OOP is rather challenging. One starting point could be to draw on existing IA frameworks used in fields related to the OOP, such as digital government [31], social innovation and integrated service delivery. In such frameworks [31] however, the approach for gathering and evaluation of indicators for impact can vary widely, from highly structural quantitative methods to highly qualitative ones. Moreover, where the end-user is taken up in many indicators in these frameworks, their presence in evaluation methods is often lacking [1]. Looking at the variety of scoring mechanisms used, it becomes clear that there is no one preferred methodology when it comes to IA's in relation to analysing digitisation in and of public services. The available frameworks 
do offer useful suggestions on how to connect various high-level goals and expected impacts to measurement indicators. In earlier work [35, 38], we described how IA's are often concerned with addressing specific issues rather than performing a generic assessment.

In case of this IA, the focus is on assessing whether the objectives of the OOP will be achieved, yet, we also acknowledge that over the course of the development of the OOP, such values may change. Existing IA frameworks offer some important points for consideration. Firstly, an IA may consist of an approach that investigates multiple criteria or requirements (such as fairness or efficiency) across multiple aspects or fields (such as environmental, economic, or organizational), leading to a two-dimensional set of indices. This allows for specific recommendations that concern a combination of criteria or requirements. Secondly, IA's that aim to assess a specific topic can yield rich, in-depth findings as opposed to IA's that evaluate several options. In other words, smalland in-depth assessment approaches might turn out more valuable than trying to capture impacts broadly and for the long term.

\subsection{A Impact Assessment Framework for the OOP}

For the development of an IA framework for the OOP, we started by discerning different levels of government processes, such as institutional and environmental, legal and regulatory, organizational and managerial, or technological, or end-user satisfaction [15]. With the first two levels taken together (befitting the topic under study), this division of impacts can be capture in the following four categories:

1) Legal and institutional;

2) Organizational and business process;

3) Technical (data, data governance, and architecture); and

4) End-user (businesses or Economic Operators, EOs).

The first category deals with legal, institutional and/or political benefits. An elaborate overview of legal boundaries and connected frameworks regarding the OOP has been developed for different application areas [17], yet how these play out in an implementation phase remains unknown. Besides 'hard' legal boundaries, institutional rules and regulations as well as political climate play a major role in shaping the preconditions for the OOP implementation. Secondly, local organizational structures and habits can differ greatly within governmental administrative bodies and institutions. Day-to-day practices are often augmented when it comes to information and data exchange between Member States and herein lie great challenges and potential impacts. The OOP, thus, does not only need to 'pass' legal and political tests, it also needs to be adopted within day-to-day administrative organizational practices. Thirdly, ICT infrastructures need to be ready for OOP implementation. Technology or technological aspects include both aspects of data (sharing and harmonization) and data architecture. Finally, businesses and other end-users represent an important stakeholder group to assess the impacts of the OOP and should be of key importance in assessment [24].

These four categories are consequently mapped against the main impact (benefit) categories of the TOOP project (administrative burden reduction, quality of service, 
government efficiency, secondary impacts) to create a matrix. In each of the crosssections of the matrix, potential impact indicators can be discerned. We have derived these indicators both based on eGovernment literature and they have been validated and extended during the project meetings with experts from the TOOP project. The indicators that are based on literature were derived from an explorative literature search. Since only few studies of the OOP specifically were found (notable exceptions being Cave [6] and Gallo et al. [14]), we explored adjacent terms and areas to widen our search. Furthermore, Gallo et al. [14] stress that the OOP is currently not, and should also not be, implemented in isolation, but rather within the wider context of eGovernment programs, being on a cross-border or a national level. Therefore, we also looked at topics related to the OOP, stemming from the wider field of eGovernment. ${ }^{2}$

Table 1 presents an overview of the indicators from each of the four categories described earlier and maps them onto the four impact categories. It should be noted that some of the impacts can be combined or shifted (e.g. simplification of the process and time/cost savings are related to user satisfaction and government efficiency as well as to administrative burden reduction). Below, the expected benefits of the OOP, based on the literature search, are summarized per TOOP objective.

\subsection{Administrative Burden Reduction}

A first expected benefit of the OOP is administrative burden reduction for end-users. This, in general, can be seen as reducing the amount of steps or simplification of a process that need to be taken for a business to comply with a specific procedure [6]. By having company data available digitally across borders, filling out forms, and walking through administrative procedures should become simplified for the end-users. This will ideally lead to a significant decrease in both time and costs of administrative procedures. Time saving is mentioned by Cave et al. [6], being savings on: process time (time spent locating, collecting and submitting information, completing administrative procedures and specifying services to the appropriate level of detail), and elapsed time (time needed to complete procedures from start to finish).

Besides operationalizing administrative burden reduction as time and cost savings, other aspects should be taken into account from the wider context of eGovernment. Bekkers et al. [43] mention the changing relations between stakeholders and the law, or in regulation in general as a major expected benefit contributing to administrative burden reduction. This is closely related to the notion of transformational e-government,

\footnotetext{
$\overline{2}$ The following search engines were used: Scopus, ResearchGate, Springer, the European Commission Database, and Google Scholar. Furthermore, sources used in the TOOP Grant Agreement were analyzed. Key search terms included 'OOP benefits', 'OOP KPI', 'OOP impact', 'eGovernment benefits', 'eGovernment KPI', 'eGovernment impact', 'eGov benefits', 'eGov KPI', 'eGov Impact', 'Impact Assessment Criteria', 'Impact Criteria', 'Integrated Service Delivery KPI', 'Integrated Service Delivery benefits', 'Integrated Service Delivery impact', and 'Integrated Service Delivery criteria'. Papers based on this search that are included in the literature review were selected on several criteria: number of expected benefits mentioned, applicability of the expected benefits as an indicator of the OOP, year of publication not older than ten years (> 2006), covering at least two different aspects, perspectives, or dimensions of impact, and maturity of the framework.
} 
Table 1. Categorisation of expected benefits, secondary benefits and negative effects, per impact level - adapted from TOOP Deliverable D2.10 [35]

\begin{tabular}{|c|c|c|c|c|}
\hline \multirow[t]{2}{*}{ Expected benefit } & \multicolumn{4}{|c|}{ Where (on which level) does the expected benefit occur? } \\
\hline & Legal and institutional & $\begin{array}{l}\text { Organizational and } \\
\text { business process }\end{array}$ & $\begin{array}{l}\text { Technical (data, data } \\
\text { governance, } \\
\text { architecture) }\end{array}$ & $\begin{array}{l}\text { End-user (businesses } \\
\text { or EOs) }\end{array}$ \\
\hline $\begin{array}{l}\text { Administrative } \\
\text { burden reduction }\end{array}$ & $\begin{array}{l}\text { - Transformation of } \\
\text { stakeholders' } \\
\text { relations and } \\
\text { legislation }\end{array}$ & $\begin{array}{l}\text { - Harmonisation of } \\
\text { data }\end{array}$ & $\begin{array}{l}\text { - Improved data } \\
\text { quality, reliability } \\
\text { and validity }\end{array}$ & $\begin{array}{l}\text { - Simplification of } \\
\text { processes } \\
\text { - Time savings } \\
\text { - Cost savings }\end{array}$ \\
\hline Quality of service & $\begin{array}{l}\text { - Non-discrimination } \\
\text { - Reliability and trust }\end{array}$ & $\begin{array}{l}\text { - Transparency and } \\
\text { accountability }\end{array}$ & $\begin{array}{l}\text { - Ubiquity, access and } \\
\text { availability }\end{array}$ & $\begin{array}{l}\text { - User acceptance } \\
\text { - Responsiveness to } \\
\text { the needs of society } \\
\text { and legitimation }\end{array}$ \\
\hline $\begin{array}{l}\text { Government } \\
\text { efficiency }\end{array}$ & $\begin{array}{l}\text { - Fraud reduction and } \\
\text { prevention }\end{array}$ & $\begin{array}{l}\text { - Avoid duplication of } \\
\text { tasks } \\
\text { - Re-use and } \\
\text { interconnectivity of } \\
\text { building blocks }\end{array}$ & $\begin{array}{l}\text { - Interoperability of } \\
\text { data }\end{array}$ & - User satisfaction \\
\hline $\begin{array}{l}\text { Secondary benefits } \\
\text { and negative } \\
\text { consequences }\end{array}$ & $\begin{array}{l}\text { - Improved } \\
\text { collaboration } \\
\text { between government } \\
\text { organisations }\end{array}$ & $\begin{array}{l}\text { - Improved } \\
\text { organisation and ICT } \\
\text { architecture } \\
\text { - Performance and } \\
\text { effectiveness } \\
\text { - Start-up effects }\end{array}$ & $\begin{array}{l}\text { - Security breaches } \\
\text { - Platform dependency }\end{array}$ & $\begin{array}{l}\text { - Improved mobility } \\
\text { - Risk of identity theft } \\
\text { - Digital dependency }\end{array}$ \\
\hline
\end{tabular}

or public sector transformation, referring to the radically changing ways in in which stakeholders interact with each other [41]. Due to novel - digital - ways of working, also relations among stakeholders alter, which in the end influences existing regulation as well. To ensure simplification of administrative processes, uniformity and consistency of data, such as adhering to standard formats with the same definitions, become essential: i.e. harmonization of data [44]. One way of achieving this is by setting up base registries [14].

This streamlining of public sector processes can take place organizationally by streamlining administrative processes, but also technologically by enabling automated data sharing and to replace redundant data collection with information requests, thereby flipping the process form dragnet-data collection to on-point information collection and sharing $[22,23]$. Furthermore, to allow for harmonization, an important expected benefit is improving the quality, reliability and validity of data [44]. Reliability of data will likely increase, as data will be stored and therefore also updated in its original source. These elements are, thus, expected to be benefits that can be attributed to the OOP as well and that are likely to lead to administrative burden reduction.

\subsection{Improved Quality of Service}

A second category of expected benefits of the cross-border OOP is improving the quality of service of public services. A main expected benefit of the OOP is non-discrimination, by removing asymmetries in the treatment of domestic and cross-border individuals and 
businesses seeking services that require them to submit information to public authorities [43]. This is considered an important benefit of the OOP in the context of establishing the Digital Single Market. Besides non-discrimination, also other public values are important to achieve in the context of public services delivery. One important expected benefit in this context increased transparency and accountability [43]. When administrative processes change and data is harmonized and standardized, this allows for greater openness of processes and data repositories, which is increasingly common within the context of open data [44].

Furthermore, an expected benefit of the OOP is ubiquity, which refers to access to a service from any platform, at any time, from any physical location, which also means that ubiquity is not limited to public services but can also be provided by private service providers [42]. More generally, accessibility is an expected benefit of the OOP, meaning the level of ease and extent of access service users have to the services to which they are eligible [54]. For public services, user acceptance is an important expected benefit [6]. The acceptance of a public service by users and the responsiveness to the needs of society [43] is especially important, since their acceptance and relevance are strong determinants for the use - and thus the benefits for end-users. Therefore, improved quality of services is expected to increase trust and reliability of government services, as more citizens will be inclined to use public services [6].

\subsection{Government Efficiency}

Regarding efficiency of government processes, a main expected benefit of the OOP is the avoidance of duplication of tasks [53]. If tasks within public administrations can be performed more efficient, this is likely to result in a decrease of time spent on these tasks as well. As such, it is a mirrored benefit from administrative burden reduction for businesses. A second important expected benefit contributing to government efficiency is fraud reduction and prevention, which can be explained as the aim to minimize the extent, and improve the detection of attempts to obtain services by means of inaccurate or contradictory information [6]. Generally, these are the two main expected benefits for government organizations.

Furthermore, to allow for re-use of data and existing architectural building blocks, re-use and interconnectivity of building blocks is an expected benefit of realizing the OOP [6], as well as achieving interoperability of data [44]. The former refers to an administration-wide simplification of information management, while the latter refers to the development and use of standards for data exchange, allowing also for a machine readable format. These benefits, too, mirror the benefits for businesses since data harmonization was already mentioned as a main expected benefit for businesses. Generally, the impact of improved data quality and data harmonization can be seen to benefit organizations beyond those within the public sector, while interconnectivity of administrative building blocks and interoperability are expected to benefit public administrations most. Still, there is expected to be a clear link between the benefits of businesses and those of government.

Another expected benefit of the OOP is user satisfaction [24]. While this benefits businesses as well, it is considered especially important for public services, since it is a strong determinant of the use of a service as well as for trust in public administration [3]. 
More efficient government is expected to lead to more satisfaction among users, which, in turn, is expected to increase not only actual use and uptake of the services, but also of trust in public administration. Here too, it can be observed that it is hard to identify expected benefits for the OOP in isolation from eGovernment benefits in general.

\subsection{Secondary Benefits and Unforeseen (Negative) Consequences}

Besides expected benefits, an IA can also include unexpected and unforeseen benefits as well as negative consequences. Therefore, in addition to the expected direct benefits, an IA should offer a framework that captures secondary and negative effects as well. This allows an impact assessment along a broader spectrum, adhering also to realistic scenarios of risks and potential bottlenecks (be they on technical, organizational, legal, or economic aspects), and it helps to differentiate an IA from a more direct project evaluation. By allowing secondary benefits to enter the assessment, it is possible to touch upon larger scale impacts of implementation of the OOP. For some benefits it is hard to distinguish whether they are direct, primary benefits or second, larger scale impacts. Examples could be fraud reduction, transparency and accountability, and improved data quality. These can either be achieved by implementing the OOP directly or as a result of having implemented the OOP. For practical reasons, since we expect that in the case of the TOOP project pilots we may be able to observe these benefits directly, we took up the these benefits under the main categories of expected benefits. Regarding the benefits that we do not expect to occur within the project (for example, because we are only able to assess pilot settings rather than actual use in practice), but that may be expected to occur after implementation in a real-life setting, we consider secondary benefits.

Secondary benefits that we have identified include increased mobility of end-users as a result of non-discrimination and general improved services across borders ${ }^{3}$. Furthermore, a secondary effect of the OOP that is likely to occur is increased or improved collaboration between governmental bodies and institutions, also the ones who are not directly linked to the first OOP projects or practices. When interconnectivity of building blocks within administrative processes, interconnectivity of data, and data harmonization occur, it is likely that public administrations are able to find new and more efficient ways to collaborate also for other purposes. Besides efficiency gains from a financial and organizational viewpoint, better organization and IT architectures were found as expected secondary benefits from the wider context of eGovernment [45]. Generally, these types of secondary effects are expected to result in increased performance and effectiveness of government or 'performing with less', referring to the combined effects of improved user satisfaction, effectiveness and efficiency [43], or as a combination of resource utilization, accuracy, efficiency, and effectiveness [46].

A possible negative consequence on the short term could be start up effects ${ }^{4}$. This means that during the initial start-up phase, investments in both time and money are needed to allow for this re-adjustment of processes and ways of working, adaptation

3 This was mentioned in one of the workshops that were held with the participants in the pilots, during the kick-off meeting Tallinn, 26 January, 2017.

4 This was mentioned in one of the workshops that were held with the participants in the pilots, during a TOOP workshop Rome 22-24 May, 2017. 
and mutual learning process between user and provider of a government service to the OOP. This likely influences the benefits identified in the assessment. A number of related aspects can be mentioned, such as the above mentioned developing organizational and IT architecture - aligning and orchestrating within and in between governmental bodies, which will likely demand a huge technical effort. This aspect can, thus, both be framed as a potential expected - secondary - benefit, but since the development may be cumbersome, this may also become a negative consequence. For end-users, start-up effects may result in (temporarily) maintaining parallel systems of digital and paper, which means that they - for a period of time - may have to maintain parallel links to government, including challenges related to archiving and data retention (think of maintaining duplicates of own or governmental digital archives, copies, user names and logins, identity verification, alteration of input, timeliness and 'freshness' of data).

Final potentially negative aspects include factors related to data security and 'lockin effects' - on both the side of government and that of end-users. If data cannot be stored safely and if data is not treated in a proper and trustworthy manner, this could result in the risks of security breaches [47] with the possible risk of identity theft [48] and as a result, the OOP has little chance of success in terms of scaling and uptake [50]. Although this in part is an organizational aspect, the technical side of responsible data processing within government organizations lies in matters such as compatibility, firmware updates, the use of open or closed platforms, inter-software dependencies etc. Furthermore, potential negative aspects include 'lock-in effects' [50] on the side of governments (platform dependency), when they become dependent on the vendor platforms used for services delivery, or on the side of end-users when they become digitally dependent on governmental systems for service delivery and data provisioning [51].

\section{Validating and Discussing the Framework with Stakeholders}

In order to further assess our framework and criteria, we asked the TOOP project members for feedback. Following our action research approach, this was done via a series of seven stakeholder sessions that took place throughout the project. ${ }^{5}$ In these sessions, project partners - (around ten to fifteen per session) developers of technical building blocks for the OOP and public administrators from different Member States - were invited to discuss the (expected) impacts of the OOP, the type of indicators proposed and how these connect to current ways of assessment of innovations in government as well as the benefits and challenges that they foresee once the OOP is implemented. In every session we refined the (expected) impacts based on the discussion and we updated the framework accordingly. In this way, through these stakeholder sessions we were not only able to validate the impact indicators identified from literature, but we could also explore to what extend the impacts that were set out at the start of the project changed due to experience gained during the development of proof-of-principles in the several pilot projects. Regarding the IA, we addressed the following questions:

\footnotetext{
${ }^{5}$ Meetings were held in Tallinn (25-27 January 2017), The Hague (18-19 April 2017), Rome (22-24 May and 2-3 October 2017).
} 
- Are the impacts you expected at the start of the pilot the same as you see them now?

- Do you think these impacts will materialize once the pilot is actually implemented and how far in the horizon do you see this happening?

- What would be the strongest felt impacts, in your opinion, and what is further needed to achieve them?

- Which issues/problems of this public service will be resolved or minimized out through TOOP architecture?

- Some of the expectations are that the OOP will increase the data quality and reliability. On what is this outcome dependent and how has the pilot/use case approached this objective?

Several points were raised during the discussions. In general impacts were expected to materialize after OOP is adopted but provided that it is adopted widely enough. Regarding changing of impacts, the participants recognized some of these impacts but noted that not all will be immediately felt and some can be seen as more important than others. As an illustration, administrative burden reduction might be reached in the long-term but it can be expected that in the short- and medium-term the administrative burden might increase until the OOP is fully implemented. Government efficiency on the other hand might be much more important while yet difficult to measure as it might also involve re-organization of some procedures. Participants also noted that some legal/regulatory impacts may need to be emphasized more. It was also pointed out that TOOP needs key business cases to communicate how it can help in achieving higher-level goals. It was also noted that the categories of impacts as presented in the framework were not necessarily recognized by practitioners: the more specific they can be made, the better. Both member state representatives and technical experts from the pilots recommended to provide clear roadmaps for implementation after the project is finished. In summary, for the sustainability of the OOP its impacts need to be clear and convincing in order to stimulate uptake.

For each of the four categories of the framework, findings were captured from the stakeholder sessions. First of all, when we look at legal and institutional impacts, some the of the scenarios for OOP implementation might be challenging, mainly because some parts of business-or citizen registration data would need to be checked on authenticity and correctness by an authorised representative each time data is manipulated. Yet, if implemented, the OOP would allow authorities to directly share data with each other (provided that an agreement from the user is given), and this would ensure authenticity of the data and leading to increased reliability. If implemented following the right procedures, also beyond the business-to-business scenario, the OOP might help in fraud reduction, as several focus group participants stated that this is a highly important goal and marker (or driver).

Secondly, on the level of organizational and business processes, the participants stress that lessons learnt from TOOP should travel to other sectors and fields (e.g. private individuals data exchange). As the possibilities for cross-border exchange of information are quite wide and the SDGR priorities do not always match with the pilot area focus, the results from the TOOP pilots should be seen as examples that can be extrapolated to other sectors. Moreover, for the sustainability of TOOP, and to get a better grip on the demand side of OOP, statistics and monitoring mechanisms can also help estimate 
the potential demand for OOP solutions in the different sectors, thus helping countries prioritise their efforts. Realizing the benefits of the OOP could, however, be influenced by a variety of organizational factors - from internal (re)organization and digitization to international coordination of efforts. In the maritime sector for instance, introducing the OOP on an international level (rather than just European) has the potential to not only reduce the time and costs of ship inspections but also help authorities with examining foreign certifications.

Thirdly, on a technical level (data, data governance, and architecture), besides the semantic mapping, for full implementation of the OOP principle and its expansion beyond the tested scenarios, the work should also continue on the interoperability of the different systems and also in exploring a 'push scenario' where foreign registries receive notifications and accept as authoritative any changes of the data they already hold, thereby reducing the administrative burden for citizens and businesses who need to only introduce changes to their situation once.

Finally, regarding end-users (businesses), there is a need to establish a clear vision on the next steps in order to provide stakeholders with a roadmap and sustain the current momentum. As the cross-border OOP is not implemented, at this time, it can only be expected that the OOP will bring convenience, time and costs savings as the biggest impacts [5].

\section{Discussion: Challenges of Measuring Impacts}

Regarding the measurement of these impacts, a first key point of debate is that of quantitative versus qualitative forms of measuring the indicators as provided above. Due to the varying levels between member states of digital readiness for the OOP, and due to the exploratory nature of the TOOP pilots, measuring quantitively for instance, the administrative burden reduction at this point in time would be based mainly on speculation. What became clear during the stakeholder sessions, is that many see the IA framework more as a preparation for sustainability: to gather what should be monitored in the future in order to actually properly measure the impact of the OOP, but that for now, it was considered too early to assess impacts, especially quantitatively. Where previous studies predicted that applying the OOP across the EU could lead to "annual net savings of as much as $€ 5$ billion per year" [14], analysis of the overall impact of the OOP is difficult to estimate. This is due to, among others, differences among Member States in the use of OOP [14], the overall strategy of the OOP, the types of data that can be shared, and the number of digitized transactions [14].

Similarly, a study on different policy options and impacts for EU-wide adoption of the OOP concluded in 2017 that the impacts of the OOP as well as the associated costs are very difficult to quantify. The study further concluded that "[t]here are significant evidence gaps on costs and benefits, especially beyond Member State level. What can be measured does not cover the most socially important impacts, is not directly attributable to OOP and is not quantitatively significant. Moreover, available measurements do not capture business or citizen impacts" [6]. Instead of assessing the impact of OOP, looking at expectations and refining indicators to measure potential impact seems within scope. It should however be noted that these impacts are, thus, only expectations. These are based 
on the experience of the TOOP participants in the field of public administration and their experience with similar previous initiatives. Plotting lessons from the stakeholder sessions among the main four levels of impact, leads to a set of reflections, including possible impacts, benefits and challenges, that we have captured.

In general, the expected benefits were not so much questioned, yet priorities in discussion within multiple focus groups tentatively indicate that burden-reduction and fraud-detection, with main concerns around personal data protection and current procedures around inter-governmental data sharing were highlighted. The SDGR is generally seen a driver for OOP as well as the TOOP project which can provide lessons learned based on the pilots. Yet with so many currently existing systems still in the process of full adoption (an ENISA study from December 2017 on the adoption of eIDAS for example, concluded that there is a difference in the penetration of classical trust services - such as insurance of certificates - and defined services by eIDAS and that for 'certain services there are only a few providers in specific Member States' [7]), it remains challenging to predict the impact of TOOP in the landscape of digital government.

\section{Conclusion}

In this chapter we have shown how an Impact Assessment framework for the OnceOnly Principle was developed and subsequently validated. Based on desk research and regular qualitative interaction with the pilots and Member State representatives, we set out to create different moments and methods of tacking stock of impacts during the development of the TOOP project. The Impact Assessment framework, developed based on these interactions and former similar Impact Assessment approaches, can help Member States to put in place processes and instruments to measure if and how the OOP is contributing to goals set by the different Member States. The main contribution of the framework is a starting point for actual measurement of impacts once first OOP-based services are put into place.

Concerning the measurement of impact, one of the main challenges is to find the right level of granularity for the impact indicators. On the one hand these indicators need to remain connected to the larger impact goals (or benefits) that the OOP is set out to bring, on the other hand, they need to be concrete to such an extent that they can connect to existing indicators. We found out that some impact indicators can be measured quantitatively, but that painting a complete picture of the impact will need qualitative work in the form of interpreting and synthesizing quantitative measurements.

Whereas the framework in itself seems to cover the main potential impacts of the OOP, the validation sessions revealed two key lessons. The first being that out of the many potential impacts, there are some that turn out be of key relevance and thus can be seen as key drivers - or potential barriers. Moreover, the way in which the impacts will be measured (quantitively or qualitatively) remains challenging especially since little is known about the size of the problem it aims to solve. This means that it is unclear if the OOP fills a latent need and/or if the lack of an OOP is currently withholding companies to engage in cross-border business. Another point of attention is the connection to current legislation and existing building blocks: these connections need to become more explicit in the pursuit of a sustainability roadmap for Member States or sectors implementing the 
OOP. The OOP has a number of potential positive impacts, recognised by the pilots and their members. It is generally agreed among the research participants that most of the impacts will materialize shortly after the OOP is implemented. This however assumes that the OOP is successfully implemented among all business registries and in a critical mass of countries. Given that many Member States are currently arranging their regional and national data sharing processes and that this might imply some re-organization of registries and rights to share, the entire process will take a longer than initially foreseen. On the other hand, regulatory reforms such as the SDGR act as an accelerator for uptake by the Member States. The pace of implementation will differ per country and sector and also the readiness of some countries differs with regard to the implementation of some of the building blocks such as eIDAS, the European digital identity framework. The impacts of implementation of OOP will differ per Member State and are dependent on factors such as digital maturity of the administration, social attitudes toward governmental data sharing, the local legal framework and perceived need for the service both within and outside the public administrations.

\section{References}

1. Akkaya, C., Krcmar, H.: Towards the Implementation of the EU-Wide "Once-Only Principle": perceptions of citizens in the DACH-region. In: Parycek, P., et al. (eds.) EGOV 2018. LNCS, vol. 11020, pp. 155-166. Springer, Cham (2018). https://doi.org/10.1007/978-3-319-98690$6 \_14$

2. Alene, A, Manyong, V., Coulibaly, O., Abele, S.: IMPACT: A Framework for conceptualizing Impact Assessment and promoting impact culture in Agricultural Research. IITA, Ibadan, Nigeria (2006)

3. Alarabiat, A., Soares, D., Fereirra, L., de Sa-Soares, F.: Analyzing e-governance assessment initiatives: an exploratory study. In: Proceedings of the 19th Annual International Conference on Digital Government Research: Governance in the Data Age, pp. 1-10, May 2018

4. Banta, D.: What is technology assessment? Int. J. Technol. Assess. Health Care 25(Supplement 1), 7-9 (2009)

5. Camilleri, M.A: Exploring the behavioral intention to use e-government services: validating the unified theory of acceptance and use of technology. In: Kommers, P. (Ed) 9th International Conference on Internet Technologies \& Society, Lingnan University, Hong Kong. IADIS (2019). https://ssrn.com/abstract=3320327.

6. Cave, J., Botterman, M., Cavallini, S., Volpe, M.: EU-wide digital Once-Only principle for citizens and businesses. policy options and their impacts. Final Report for the European Commission, DG CONNECT (2017). https://doi.org/10.2759/393169

7. ENISA: eIDAS: Overview on the implementation and uptake of Trust Services: One year after the switch over. European Union Agency for Network and Information Security (ENISA), December 2017

8. European Commission, European eGovernment Action Plan 2016-2020. https://ec.europa.eu/ digital-single-market/en/european-egovernment-action-plan-2016-2020. Accessed 29 Sept 2020

9. European Commission, eGovernment Action Plan. https://ec.europa.eu/digital-single-mar ket/en/egovernment-action-plan-digitising-european-industry. Accessed 29 Sept 2020

10. European Commission, Impact assessments - the need for impact assessment. https://ec.eur opa.eu/info/law-making-process/planning-and-proposing-law/impact-assessments_en; 
11. European Commission: European Interoperability Framework - Implementation Strategy. Communication COM(2017) 134 final (2017)

12. European Commission, The single digital gateway. https://ec.europa.eu/growth/single-mar ket/single-digital-gateway_en

13. Eurostat - Statistics Explained. https://ec.europa.eu/eurostat/statistics-explained/index.php/ Glossary:European_Economic_Area_(EEA)

14. Gallo, C., Giove, M., Millard, J., Thaarup, R.K.V.: Study on eGovernment and the Reduction of Administrative Burden: final report (2014). https://doi.org/10.2759/42896.

15. Gil-Garcia, J.R., Pardo, T.: E-government success factors: mapping practical tools to theoretical foundations. Gov. Inf. Q. 22, 187-216 (2005)

16. Glasson, J., Therivel, R., Chadwick, A.: Introduction to Environmental Impact Assessment. Fourth Edition, Routledge (2012)

17. Graux, H.: Overview of legal landscape and regulations. Deliverable 2.5, TOOP project (2017)

18. Henman, P.: Of algorithms, apps and advice: digital social policy and service delivery. J. Asian Public Policy 12(1), 71-89 (2019)

19. Henning, F.: A theoretical framework on the determinants of organisational adoption of interoperability standards government information networks. Gov. Inf. Q. 35(4), S61-S67 (2018)

20. Kalvet, T., Toots, M., Krimmer, R.: D2.7 Drivers and Barriers for OOP (1st version). Deliverable D2.7 for the TOOP project (2017). http://toop.eu/sites/default/files/D27_Drivers_and_ Barriers.pdf.

21. Kalvet, T., Toots, M., Van Veenstra A.F., Krimmer, R.: Cross-border e-Government services in Europe: expected benefits, barriers and drivers of the once-only principle. In: Proceedings of the 11th International Conference on Theory and Practice of Electronic Governance, pp. 6972, April 2018

22. Krimmer, R., Kalvet, T., Toots, M., Cepilovs, A.: Position Paper on Definition of the "OnceOnly" Principle and Situation in Europe. Deliverable D2.6 of the TOOP project (2017). http:// toop.eu/assets/custom/docs/TOOP_Position_Paper.pdf

23. Krimmer, R., Kalvet, T., Toots, M.: Position paper on definition of OOP and situation in Europe (version V1.0). Deliverable D2.14 for the TOOP project (2017). http://www.toop.eu/ sites/default/files/D2.14_Position_paper_OOP_update.pdf

24. Mitseva, A., Peterson, C.B., Dafoulas, G., Efthymiou, A., Abildgaard, A., Bellini, S.: ISISEMD evaluation framework: for impact assessment of ICT pilot services for elderly with mild dementia, living in the community and their relatives. In: Proceedings of the Networking and Electronic Commerce Research Conference 2010, pp. 1-23. American Telecommunications Systems Management Association (2010)

25. Mocan, A., Facca, F.M., Loutas, N., Peristeras, V., Goudos, S.K., Tarabanis, K.: Solving semantic interoperability conflicts in cross-border e-government services, Semantic Services, Interoperability and Web Applications: Emerging Concepts. IGI Global, pp. 1-47 (2011)

26. Nielsen, M.M., Carvalho, N.R., Veiga., L.G., Barbosa, L.S.: Administrative burden reduction over time: literature review, trends and gap analysis. In: Proceedings of the 10th International Conference on Theory and Practice of Electronic Governance, pp. 140-148, March 2017

27. OECD Directorate For Science, Technology And Innovation: What is Impact Assessment. OECD, pp. 1-7 (2014). https://www.oecd.org/sti/inno/What-is-impact-assessment-OECDIm pact.pdf.

28. Passani, A.: Impact Assessment of Collective awareness Platform for Social innovation and Sustainability (CAPS) - the IA4SI framework. IA4SI project (2014)

29. Podhora, A., et al.: The policy relevancy of impact assessment tools: evaluating nine years of European research funding. Environ. Sci. Policy 31, 85-95 (2013)

30. Sanderson, I.: Evaluation, policy learning and evidence-based policy making. Public Adm. 80(1), 1-22 (2002) 
31. Savoldelli, A., Misuraca, G., Codagnone, C.: Measuring the Public value of e-Government: The eGEP2. 0 model. Electron. J. e-Government, 11(1), 373-388 (2013)

32. Sivarajah, U., Irani, Z., Weerakkody, V.: Evaluating the use and impact of Web 2.0 technologies in local government. Gov. Inf. Q. 32, 473-487 (2015)

33. Streatfield, D., Markless, S.: What is impact assessment and why is it important? Perform. Meas. Metrics 10(2), 134-141 (2009)

34. Tepandi, J., et al.: Towards a cross-border reference architecture for the once-only principle in europe: an enterprise modelling approach. In: Gordijn, J., Guédria, W., Proper, H.A. (eds.) PoEM 2019. LNBIP, vol. 369, pp. 103-117. Springer, Cham (2019). https://doi.org/10.1007/ 978-3-030-35151-9_7

35. Timan, T., Karanikolova, K., Van Veenstra, A.F.: The Once-Only Principle Project 2nd Evaluation Report; Impact Assessment Framework - update. Deliverable D2.10 for the TOOP project, confidential (2019)

36. TOOP: Implementation of TOOP Solution: Italian Success Story. TOOP project. https://toop. eu/sites/default/files/italian-v2.pdf

37. TOOP: Implementation of TOOP Solution: Norwegian Success Story. TOOP project. https:// toop.eu/sites/default/files/norway-v6_03.pdf

38. Van Veenstra, A.G., Timan, t., Vermeulen, P., Congleton, H.: D2.9 OOP Impact Assessment framework (final version). Deliverable D2.9 for the TOOP project (2018)

39. Yannacopoulos, D., et al.: E-Government: a comparative study of the G2C online services progress using multi-criteria analysis. Int. J. Dec. Support Syst. Technol. 2(4), 1-12 (2010)

40. Zamboni, A., et al.: ICT Impact Assessment Guidelines: Practical tools and guidelines for assessing ICT implications. European Commission (2018)

41. van Veenstra, A.F., Klievink, B., Janssen, M.: Barriers and impediments to transformational government: insights from literature and practice. Electron. Gov. Int. J. 8(2/3), 226-241 (2011)

42. van Veenstra, A.F., et al.: Ubiquitous Developments of the Digital Single Market. European Parliament's Committee on Internal Market and Consumer Protec-tion, Brussels (2013). http://www.europarl.europa.eu/RegData/etudes/etudes/join/2013/507481/IPOLIMCO_ET(2013)507481_EN.pdf.

43. Bekkers, V., Tummers, L, Stuijfzand, B.G., Voorberg, W.: FP7 LIPSE - Social Innovation in the Public Sector: An Integrative Framework. Working Paper Erasmus University Rotterdam, Version 0.5 (2013). http://lipse.org/userfiles/uploads/Working\%20paper\%201\%20Bekkers\% 20et\%20al.pdf.

44. Zuiderwijk, A., Janssen, M.: Open data policies, their implementation and impact: a framework for comparison. Gov. Inf. Q. 31(1), 17-29 (2013)

45. Codagnone, C., Boccardelli, P.: eGovernment Economics Project (eGEP) - Measurement Framework Final Version, 2006. European Commission (2006). http://www.umic.pt/images/ stories/publicacoes200709/D.2.4_Measurement_Framework_final_version.pdf.

46. Fotrousi, F., Fricker, S.A., Fiedler, M., Le-Gall, F.: KPIs for software ecosystems: a systematic mapping study. In: Lassenius, C., Smolander, K. (eds.) ICSOB 2014. LNBIP, vol. 182, pp. 194-211. Springer, Cham (2014). https://doi.org/10.1007/978-3-319-08738-2_14

47. Alsmadi, I., Abu-Shanab, E.: E-government website security concerns and citizens' adoption. Electron. Gov. Int. J. 12(3), 243-255 (2016)

48. Whitson, J.R., Haggerty, K.D.: Identity theft and the care of the virtual self. Econ. Soc. 37(4), 572-594 (2008)

49. Veugelers, R.: New ICT sectors: Platforms for European growth? Bruegel Policy Contribution, issue 2012/14, August 2012. https://lirias.kuleuven.be/bitstream/123456789/376464/2/New.

50. Farrell, J., Klemperer, P.: Coordination and lock-in: competition with switching costs and network effects. Handb. Ind. Organ. 3, 1967-2072 (2007)

51. Reddick, C.G.: Citizen interaction with e-government: from the streets to servers? Gov. Inf. Q. 22(1), 38-57 (2005) 
52. Eden, C., Ackermann, F.: Theory into practice, practice to theory: action research in method development. Eur. J. Oper. Res. 271(3), 1145-1155 (2018)

53. European Social Network (ESN): Policy Areas: Integrated Services. ESN website. http:// www.esn-eu.org/integrated-services/index.html.

54. Richardson, D., Patana, P.: Integrating Service Delivery: why, for who, and how? OECD, Social Policy Division Discussion paper (2012). https://www.oecd.org/els/soc/Richardson_P atana\%20INTEGRATING\%20SERVICE\%20DELIVERY\%20WHY\%20FOR\%20WHO\% 20AND\%20HOW.pdf

55. Carvalho, J., Soares, D.: Who is measuring What and How in EGOV Domain? In: Parycek, P., et al. (eds.) EGOV 2018. LNCS, vol. 11020, pp. 120-131. Springer, Cham (2018). https:// doi.org/10.1007/978-3-319-98690-6_11

Open Access This chapter is licensed under the terms of the Creative Commons Attribution 4.0 International License (http://creativecommons.org/licenses/by/4.0/), which permits use, sharing, adaptation, distribution and reproduction in any medium or format, as long as you give appropriate credit to the original author(s) and the source, provide a link to the Creative Commons license and indicate if changes were made.

The images or other third party material in this chapter are included in the chapter's Creative Commons license, unless indicated otherwise in a credit line to the material. If material is not included in the chapter's Creative Commons license and your intended use is not permitted by statutory regulation or exceeds the permitted use, you will need to obtain permission directly from the copyright holder.

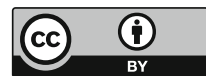

